\title{
Combined Energy Dispersive Spectrometry/Wavelength Dispersive Spectrometry Analysis of Geological Materials Using an Electron Probe Microanalyzer
}

\author{
Emma S. Bullock ${ }^{1}$ \\ 1. Geophysical Laboratory, Carnegie Institution of Washington, Washington, DC.
}

In recent years, there has been much discussion of the merits and drawbacks of Energy Dispersive Spectrometry (EDS) analysis versus Wavelength Dispersive Spectrometry (WDS) [e.g. 1, 2]. Both techniques have distinct advantages and disadvantages. For EDS, the advantages include ease of use (with one click, a user can collect an entire spectra of the elements present in their sample, and software comes with automatic peak identification); speed of acquisition (depending on how the system is set up, a representative qualitative spectra can be collected in a matter of seconds); and stability of the EDS system. The disadvantages include the lower energy resolution of the detection system $(\sim 130 \mathrm{eV})$, which can cause problems resolving interferences between elements with similar x-ray emission energies [e.g. 3]; lower count rate; and reports of lower reproducibility. In contrast, WDS analyses have better energy resolution $(\sim 10 \mathrm{eV})$ allowing for better peak discrimination; higher count rates, and better light element analysis. The downside of WDS analyses include more complex procedures required to set the instrument up; and the ability to only analyze for a limited number of elements at once, which can result in longer analysis times.

In this work, we combine WDS and EDS to quantitatively analyze geological materials, in order to try and take advantage of the positive aspects of both techniques and minimize the downsides. We use two different systems, both of which are situated on the JEOL 8530F FE electron probe at the Carnegie Institution for Science in Washington, DC. This instrument is equipped with both a $30 \mathrm{~mm}^{2}$ JEOL EDS detector, and a $30 \mathrm{~mm}^{2}$ Thermo Scientific EDS detector utilizing the Noran System 7 software. The electron probe at Carnegie has five WDS detectors, each equipped with two crystals, and runs both the JEOL software and Probe for EPMA software.

Two types of geological material were chosen for analysis: carbonates (calcite, dolomite and siderite), and basaltic glass. The idea of this study was to determine the precision and accuracy of measurements made by collecting major element data on the EDS systems, and minor elements on the WDS system. For carbonates, $\mathrm{Ca}$ was determined using EDS, while $\mathrm{Mg}, \mathrm{Sr}, \mathrm{Fe}$ and $\mathrm{Si}$ were determined using WDS. For basaltic glass, Mg, Si and Fe were collected using EDS, and $\mathrm{Na}, \mathrm{K}$, Ti, S, Al and Ca were collected using WDS. Analysis of both the carbonates and the basaltic glass were obtained using both the JEOL software/JEOL EDS combination, and the Probe for EPMA/Thermo combination, in order to compare results between the different systems. The analytical conditions for all of the analyses were $15 \mathrm{kV}, 20 \mathrm{nA}$, and a $10 \mu \mathrm{m}$ electron beam. All of the samples analysed were flat, polished thin sections.

The Probe for EPMA/Thermo combination worked well for both carbonates and volcanic glasses (Table 1, 2), although the value for $\mathrm{CaO}$ in dolomite was a little higher than the published value. Standardization of the Thermo EDS system via Probe for EPMA proved to be very straightforward, as it could be combined with standardization for WDS elements. The JEOL EDS/JEOL software combination produced acceptable results for the basaltic glass (see Table 2), although standardizing the EDS system was less straightforward. Analysis of the carbonate samples by the JEOL/JEOL system produced data close to the published values for both dolomite and siderite (although again, the $\mathrm{CaO}$ 
value in dolomite is a little high). Analysis of calcite highlighted an interesting software glitch: the analysis was initially entered as an oxide, without $\mathrm{CO}_{2}$ as a calculated component, and attempts to reprocess the data offline to include $\mathrm{CO} 2$ were unsuccessful. We anticipate that this issue will be resolved by software updates in the future. In summary, using a combination of EDS and WDS to analyse materials can produce data that is comparable to data collected using WDS alone, while reducing analysis time.

References:

[1] H. A. Lowers and P. K. Carpenter, Microsc. Microanal. 21 (2015), p. 0939.

[2] P. T. Pinard et al, Microsc. Microanal. 21 (2015), p. 0938.

[3] P. McSwiggen, http://www.mcswiggen.com/TechNotes/WDSvsEDS.htm.

\begin{tabular}{|c|c|c|c|c|}
\hline \multicolumn{2}{|l|}{ Calcite } & \multirow[b]{2}{*}{$\begin{array}{c}\text { Published } \\
\text { value }\end{array}$} & \multicolumn{2}{|c|}{ Average values } \\
\hline Element & EDS/WDS & & $\begin{array}{c}\text { PfE } \\
(n=30)\end{array}$ & $\begin{array}{l}\text { JEOL } \\
(n=5)\end{array}$ \\
\hline $\mathrm{CaO}$ & EDS & 56.09 & 55.81 & 57.21 \\
\hline $\mathrm{MgO}$ & WDS & $\mathrm{N} / \mathrm{A}$ & 0.00 & 0.00 \\
\hline $\mathrm{MnO}$ & WDS & $\mathrm{N} / \mathrm{A}$ & 0.16 & 0.00 \\
\hline $\mathrm{FeO}$ & WDS & N/A & 0.03 & 0.00 \\
\hline $\mathrm{SrO}$ & WDS & $\mathrm{N} / \mathrm{A}$ & 0.00 & 0.00 \\
\hline $\mathrm{CO}_{2}$ & Calculated & 44.01 & 43.83 & $0.00 *$ \\
\hline \multirow[t]{2}{*}{ Total } & & 100.1 & 99.84 & 73.21 \\
\hline & & & \multicolumn{2}{|c|}{${ }^{*} \mathrm{CO}_{2}$ not calculated } \\
\hline \multicolumn{2}{|l|}{ Dolomite } & & \multicolumn{2}{|c|}{ Average values } \\
\hline Element & EDS/WDS & $\begin{array}{c}\text { Published } \\
\text { value }\end{array}$ & $\begin{array}{c}\text { PfE } \\
(n=25)\end{array}$ & $\begin{array}{c}\text { JEOL } \\
(n=10)\end{array}$ \\
\hline $\mathrm{CaO}$ & EDS & 30.56 & 32.24 & 33.86 \\
\hline $\mathrm{MgO}$ & WDS & 22.04 & 21.43 & 21.67 \\
\hline $\mathrm{MnO}$ & WDS & N/A & 0.02 & $\mathrm{~N} / \mathrm{A}$ \\
\hline $\mathrm{FeO}$ & WDS & $\mathrm{N} / \mathrm{A}$ & 0.12 & $\mathrm{~N} / \mathrm{A}$ \\
\hline $\mathrm{SrO}$ & WDS & $\mathrm{N} / \mathrm{A}$ & 0.00 & $\mathrm{~N} / \mathrm{A}$ \\
\hline $\mathrm{CO}_{2}$ & Calculated & 46.94 & 46.69 & 43.67 \\
\hline Total & & 99.54 & 100.50 & 99.20 \\
\hline \multicolumn{2}{|l|}{ Siderite } & & \multicolumn{2}{|c|}{ Average values } \\
\hline Element & EDS/WDS & $\begin{array}{c}\text { Published } \\
\text { value }\end{array}$ & $\begin{array}{c}\text { PfE } \\
(n=25)\end{array}$ & $\begin{array}{c}\text { JEOL } \\
(n=10)\end{array}$ \\
\hline $\mathrm{CaO}$ & EDS & $\mathrm{N} / \mathrm{A}$ & 0.01 & 0.00 \\
\hline $\mathrm{MgO}$ & WDS & $\mathrm{N} / \mathrm{A}$ & 0.13 & 0.14 \\
\hline $\mathrm{MnO}$ & WDS & 2.95 & 2.91 & 3.00 \\
\hline $\mathrm{FeO}$ & WDS & 59.08 & 59.23 & 59.24 \\
\hline $\mathrm{SrO}$ & WDS & $\mathrm{N} / \mathrm{A}$ & 0.02 & 0.00 \\
\hline $\mathrm{CO}_{2}$ & Calculated & 37.88 & 37.42 & 38.29 \\
\hline Total & & 99.91 & 99.72 & 100.66 \\
\hline
\end{tabular}

\begin{tabular}{|c|c|c|c|c|}
\hline \multirow{2}{*}{$\begin{array}{c}\text { Basaltic Glass } \\
\mathbf{8 1 2} \\
\text { Element }\end{array}$} & \multirow[b]{2}{*}{ EDS/WDS } & \multirow[b]{2}{*}{$\begin{array}{c}\text { Published } \\
\text { value }\end{array}$} & \multicolumn{2}{|c|}{ Average values } \\
\hline & & & $\begin{array}{c}\text { PfE } \\
(n=50)\end{array}$ & $\begin{array}{c}\text { JEOL } \\
(n=20)\end{array}$ \\
\hline $\mathrm{MgO}$ & EDS & 14.56 & 14.54 & 13.92 \\
\hline $\mathrm{SiO}_{2}$ & EDS & 38.42 & 38.40 & 39.43 \\
\hline $\mathrm{Na} 2 \mathrm{O}$ & WDS & 3.59 & 3.59 & 3.72 \\
\hline $\mathrm{K}_{2} \mathrm{O}$ & WDS & 1.31 & 1.33 & 1.10 \\
\hline $\mathrm{TiO}_{2}$ & WDS & 3.90 & 3.90 & 3.92 \\
\hline $\mathrm{SO}_{3}$ & WDS & N/A & 0.02 & N/A \\
\hline $\mathrm{Fe}_{2} \mathrm{O}_{3}$ & EDS & 13.43 & 13.31 & 12.91 \\
\hline $\mathrm{Al}_{2} \mathrm{O}_{3}$ & WDS & 10.41 & 10.55 & 10.72 \\
\hline $\mathrm{CaO}$ & WDS & 13.19 & 13.19 & 12.89 \\
\hline $\mathrm{P}_{2} \mathrm{O}_{5}$ & N/A & 0.96 & N/A & N/A \\
\hline Total & & 99.77 & 98.83 & 98.59 \\
\hline
\end{tabular}

Table 1. (left): Analysis of carbonates standards using a combination of EDS and WDS. Two systems were used: Probe for EPMA combined with a Thermo EDS system ("PfE"), and a JEOL EDS system combined with JEOL software ("JEOL"). In each case, $\mathrm{CO}_{2}$ was calculated rather than analysed. The results are comparable to analyses obtained using WDS analysis.

Table 2. (above): Analysis of basaltic glass using a combination of EDS and WDS. The results are extremely close to the published values. 